Original Research Paper

\title{
Personality Traits and Exposure to Stressful Life Events Among Smokers and Nonsmokers
}

\author{
${ }^{1}$ Nataša Šimić, ${ }^{2}$ Arta Dodaj and ${ }^{3}$ Kristina Sesar \\ ${ }^{I}$ Department of Psychology, University of Zadar, Zadar, Croatia \\ ${ }^{2}$ Department of Psychology, Faculty of Philosophy, University of Mostar, Mostar, Bosnia and Herzegovina \\ ${ }^{3}$ Center for Menatl Health, Šroki Brijeg Health Care Center, Bosnia and Herzegovina
}

Article history

Received: 07-08-2014

Revised: 08-10-2014

Accepted: 31-12-2014

Corresponding Author:

Arta Dodaj,

Department of Psychology,

University of Zadar, Zadar, Croatia

Email: artadodaj@gmail.com

\begin{abstract}
Early studies supposed that personality traits and students' life, which include brings many social and academic changes, may be relevant factors in initiation and maintenance of smoking. The aims of this study were to investigate differences in personality dimensions, as well as exposure to stressful life events among students' smokers and nonsmokers and finally to examine the predictive contribution of these variables to smoking status. The study was conducted on the sample of 200 students from the University of Mostar, with a median age of 21 (interquartile range, 3) who completed Goldberg's Personality Questionnaire and Scale of stressful life events. The group of students who never smoke $(\mathrm{N}=101)$ and the group of smokers $(\mathrm{N}$ =99) took part in the study. The results have shown that personality dimension of neuroticism and stressful life events related to social alienation, academic failure and everyday social conflict differed the smokers and non-smokers group. The smokers had higher scores in comparison to non-smokers group of students. Neuroticism and stressful life events academic failure and academic maladjustment were also significant predictors to smoking status.
\end{abstract}

Keywords: Five-Factor Model of Personality, Smoking, Stressful Life Events

\section{Introduction}

According to a report from the World Health Organization (WHO, 2002), tobacco smoke causes numerous respiratory and coronary diseases, as well as increased mortality. Although attention to biological and psychosocial risk smoking factors was addressed, personality characteristic were shown as the most powerful determinant of behavior. It has been established, in recent years, that five-factor model of Costa and McCrae (1992) is quite important in analyze different aspect of behavior. The model assumes the organization of personality traits in five basic dimensions which include extraversion, agreeableness, conscientiousness, neuroticism and openness to experience.

Difference between smokers and nonsmokers has been well studied but the results are not entirely consistent in different studies. Numerous researches consistently demonstrate significant differences among smokers and nonsmokers in neuroticism and extraversion. It was found that smokers compared to nonsmokers had scores on neuroticism and extraversion scales (Van Loon et al., 2001; Vink et al., 2003). Eysenck (1981) argued that individuals high in extraversion smoke in reaction to stimulation, while individuals high in neuroticism smoke to reduce tension and anxiety. However, more recent studies did not support the relationship between extraversion and addiction to tobacco products (Gilbert and Gilbert, 1995; Malouff et al., 2006; Terracciano and Costa, 2004), while relationship between neuroticism and smoking habit is confirmed (Cosci et al., 2009; Kawakami et al., 2000; Papakyriazi and Joseph, 1998; Patton et al., 1997). Some authors (Gilbert and Gilbert, 1995) found that more neurotic individuals are less inclined to stop smoking and when coped with the recent social pressure they can feel greater need for nicotine products compared to individuals who are more emotionally stable. Fewer studies have examined the association of smoking status with other dimensions of the five-factor model of personality. In the longitudinal study, Kubicka et al. (2001) showed that low conscientiousness in children was a significant predictor of smoking in adulthood, while neuroticism and extraversion were not. 
Furthermore, numerous studies have showed that low conscientiousness is associated with large risk behavior such as alcohol consummation and poor nutritional habits (Booth-Kewley and Vickers, 1994; Hagger-Johnson et al., 2012; Vollrath et al., 1999; Vollrath and Torgersen, 2002).

Furthermore, some studies have showed that smokers compared to nonsmokers achieve higher results on Eysenck's dimension of psychoticism (Arai et al., 1997; Burch et al., 2008; Spielberger and Jacobs, 1982) which is related with low conscientiousness and agreeableness. Vollrath et al. (1999) also found negative relation between smoking and agreeableness. Based on the results of previous studies, it can be concluded that neuroticism and conscientiousness are significant personality variables for to distinguish smokers and nonsmokers. It was found that individuals with high score on neuroticism scale but not on dimension of conscientiousness have uncontrolled style of impulse (Costa et al., 2000). This style could explain their addiction to nicotine in comparison to relaxed style, which is characterized by low neuroticism and conscientiousness, as well as those with excessive control style (high on both dimensions) and direct style (high on conscientiousness and low on neuroticism). However, there is lack of scientific data about smoking habit in people with different style of personality. Although smoking habits are formed during adolescence (Akram et al., 2011; Naing et al., 2004; Paavola et al., 1996), recent studies show that prevalence of smoking increases dramatically during twenties years of life (ALA, 2002; Baron-Epel and Haviv-Messika, 2004).

Student's life brings changes in the academic and social environment which can result in stress and consequently an increased alcohol and nicotine consummation. Financial difficulties and time pressures of organization time are also sources of stress in the students' population (Misra, 2000). Students of first year are particularly vulnerable group due to the inherent conflicts and frustrations that occur as a result of new demands, as well as coping with unfamiliar and new situations (Misra, 2000). They also have not social support and appropriate coping stress skills (Allen and Heibert, 1991, Wang and Castaneda-Sound, 2008).

Based on the results of previous studies it could be expected significant differences in five-factor's model of personality considering the smoking status. Differences in personality dimensions could also contribute to the differences in various stressful life events such as conflicts and frustration, social alienation, academic failure during studying between student who smoke and those who never consume tobacco products. Because neurotic persons are more anxious, insecure and poor mood, intensity of their negative emotional reactions may cause more conflicts in social environment. Individuals with low conscientiousness tend to be more disorganized, careless and irresponsible, as well as have lower academic achievement compared to persons high on the conscientiousness (Botvin et al., 1994; Pierce et al., 1996). These personality characteristics may also contribute to the increased risk of smoking.

The aims of this study were to investigate differences in personality dimensions, as well as exposure to stressful life events among students' smokers and nonsmokers and finally to examine the predictive contribution of these variables to smoking status.

\section{Materials And Methods}

\section{Participants}

The study included 216 students (163 female and 53 male) at the University of Mostar, aged from 19 to 26 years. Results of 16 participants with chronic diseases were excluded from the analysis.

For the purpose of this study participants were divided into groups of smokers $(\mathrm{N}=99,49.50 \%)$ and non-smokers $(\mathrm{N}=101,50.50 \%)$. A classification of the participants into smokers and non-smokers group was performed on the basis of their report whether they smoke. If they smoke, they have to specify how many cigarettes smoked per day. A group of smokers consisted of students who smoke at least three cigarettes per day and maximum number of smoked cigarettes was 60 . Mean score of smoked cigarettes was 7.79 (SD $=11.13)$. Smokers and nonsmokers did not differ in age $(\mathrm{F}=2,62$, $\mathrm{p}>0.10, \mathrm{df}=1 / 198)$ and gender $(\chi 2=0.02, \mathrm{p}>0.05, \mathrm{df}=1)$.

\section{Instruments}

For the purpose of this study, Sociodemographic Questionnaire has been developed. Questionnaire included data about student's gender, age, year of study, diagnosis of chronic disease and smoking status. The participants asked several questions: Do they smoke cigarettes, did they ever smoke in life and if they did how long they had been smoking. Participant who smoked had to tell the number of cigarette which they smoke per day.

Goldberg Big-Five Personality Inventory was used to measure five dimensions of personality: Extraversion, agreeableness, conscientiousness, neuroticism and openness to experience. It contained 240 items rated on a five-point Likert scale. Reliability coefficients are from 0.79 to 0.87 (Steptoe and Wardle, 2001). The alpha coefficients of internal consistency in our study are from 0.69 to 0.79 , while the reliability of the whole Questionnaire was 0.83 .

Exposure to stressful events was examined using a Scale of stressful life events (Inventory of College Students Recent life experience; ICSR), which was constructed, on the basis of Lazarus's stress model, for measuring stress on Canadian students (Kohn et al., 1990). 
ICSR scale is widely used on the students' population for testing incidence of everyday stressful events associated with studying. Original or adapted ICSR was used on samples of Canadian students, as well as students from other cultures (Bodenhorn et al., 2007; Cheng, 2003; Lay and Safdar, 2003; Vollrath, 2000). Its use in this study was approved by the Lafreniere, the author of the questionnaire. For the purpose of this study, the scale was translated into Croatian language using back translation approach. It was translated from English to Croatian and vice versa. After this procedure, it was followed review of translation by two independent experts in the field of stress and final version was constructed by their harmonization.

The scale consists of 49 items and the students were asked to assess the extent of their experience with stressful events over the past month on the 4point scale (from $1=$ "Not at all part of my life" to 4 = "Very much part of my life").

Original scale has seven subscales: Developmental challenge, time pressure, academic alienation, romantic problems, assorted annoyances, general social mistreatment and friendship problems. Alpha coefficients of scale, obtained by (Kohn et al., 1990) were 0.88 for male and 0.89 female, while for subscales ranged from 0.47 to 0.80 . Reliability obtained in other studies is also satisfactory (Bodenhorn et al., 2007; Cheng, 2003; Lay and Safdar, 2003; Vollrath, 2000).

\section{Data Collection}

Data were collected in the summer semester during the lectures. Group application of Questionnaires included the study units and there is no time limited. On average, it lasted about $15 \mathrm{~min}$. The participants were explained how to fill the Questionnaires and the anonymity was emphasized. Each participant first filled out the Sociodemographic Questionnaire, while sequence of application the Scale of stressful life events and Goldberg Big-Five Personality Inventory was rotated by the principle of ABBA. Thus, half of participants first filled the Scale of stressful life events and then Goldberg Big-Five Personality Inventory, while the other half of participants worked inversely. The study took into account ethical rules such as having the right to refuse participation, as well as not asking participants about their reasons for doing so.

\section{Results}

\section{Factor Structure of Scale of Stressful Life Events}

A method of common factor analysis was conducted on the ICSR scale using data from the initial sample of college students. The Kaiser-Guttman latent root procedure (Kaiser criterion) was used to determine the number of factor. According to this criterion, factors that are retain are those that have characteristic value equal to or greater than 1.00 . Ten factors had the characteristic value greater of one. This factor solution could be expected if we take into account the diversity of items that constitute ISCRLE scale. Therefore, in order to obtain interpretable factors, common factor analysis was then performed and the structure was rotated to orthogonal solution as it best approximated simple structure. Because Kaiser criterion shows a tendency of hyperfactorization (Mejovšek, 2003), additional criterion in decision of factor number was Cattel scree test, as well as interpretability of extracted factors. Although Cattel scree test suggests three-factor solution, it was decided to retain five factors which are interpretable. All items also had satisfactory factor loading greater than 0.30 .

Because first factor was saturated with items related with loneliness, social isolation and dissatisfaction with position in society ("I felt lonely", "I was rejected from the society"), it was interpreted as a factor of social alienation, which contains six items and explains $7 \%$ of the variance.

The second factor was factor of time pressure which contains 13 items and explains $7.51 \%$ of the variance. The items with the highest saturation of this factor were: "I didn't have enough time for leisure activities", "I didn't have enough time to complete daily tasks," "I'm not sleeping enough".

Items saturated with third factor were mainly related to problems in executing academic obligations and dissatisfaction with their abilities. Examples of items saturated with this factor are "I am dissatisfied with my learning abilities" and "I have achieved lower scores than expected." The factor contains six items that explain $8.70 \%$ of the variance and considering the content of items, it was named as Factor of academic failure.

By fourth factor, which contains 18 items, it was explained $7.37 \%$ of the variance. This factor was saturated with items related to conflicts with teachers and peers ("I have confronted with an assistant “, „I have confronted with a professor"), as well as with items related to everyday disappointments ("I have lost the confidence of a friend", "I have feel used"). Because of that reason, it was decided to name the factor as Everyday social conflict.

The fifth factor consists of six items related to college unhappiness ("I found study repulsive", "I felt an aversion toward some colleagues,") and explains $4.96 \%$ of the variance. It is a relatively homogeneous factor that according to items context indicate on student's maladjustment. Therefore, it was interpreted as the factor of Aademic maladjustment.

The factor structure of five factors explains $35.54 \%$ of the variance. Considering significant and mostly moderate correlations between factors (Table 1) it is possible to form the overall score on the Scale of stressful life events.

Factor analysis with a fixed number of common factors (one factor) showed one factor solution with a 
characteristic value greater than one which explained $31.90 \%$ of the variance.

Alpha coefficient of internal reliability was also examined and high Cronbach alpha was obtained $(\alpha=$ 0.89 ). Furthermore, extracted factors showed satisfactory reliability. Alpha coefficients, as well as other statistical parameters are shown in Table 2.

In further analyzes, the results of the subscales are formed as a linear combination of factors scores.

\section{Differences in Personality Traits and Everyday} Stressful Life Events Among Smokers and Nonsmokers

For determining the difference in the examined personality traits among smokers and nonsmokers, oneway analysis of variance was used. The results of analysis of variance, as well as the mean and standard deviation for personality dimension among smokers and nonsmokers are shown in Table 3. It was found that smokers differ from nonsmokers only on the subscale of neuroticism. Smokers achieved higher scores compared to nonsmokers (Table 3).

Furthermore, we found significant differences in stressful life events among smokers and nonsmokers. Smokers achieved higher scores than nonsmokers on the subscales of social alienation, academic failure, as well as everyday social conflict. Results on the scale were also higher on smokers compared to nonsmokers (Table 4).

In further analysis it was examined correlations between personality traits and everyday stressful life events (Table 5). Agreeableness and openness to experience were not in significant correlations with stressful life events. A higher results on dimension of extroversion were associated with lower levels of social alienation and academic failure. Higher results on dimension of conscientiousness were associated with less experience of academic failure and maladjustment, as well as everyday social conflicts. As was expected, higher levels of neuroticism were associated with higher scores on all subscales of the Scale of stressful life events (Table 5).

Regarded to the personality dimensions, only neuroticism was significantly associated with the number of cigarettes smoked per day $(r=0.12, p<0.05)$. Number of smoked cigarettes was also significantly and positively associated with frequent experiencing of social alienation $(\mathrm{r}=0.20, \mathrm{p}<0.05)$, academic failure $(\mathrm{r}=0.20, \mathrm{p}<0.05$ and everyday social conflicts $(\mathrm{r}=0.19, \mathrm{p}<0.05)$.

\section{Personality Traits and Everyday Stressful Life Events as Predictors of Smoking Statuss}

In order to predict smoking status among two dependent variables (personality trait and everyday stressful life events) a few series of sequential binary logistic regression analyses were performed. In the first step of the first two analyses, five personality dimensions were entered as predictor variables and in the second step, among them were included and stressful life events.

The results of the analysis with personality trait showed that there was a good model fit when five factor personality dimensions were included in the first step $(\chi 2$ $=7,68 ; \mathrm{df}=5 ; \mathrm{p}<0,05)$ which means that personality traits significantly predicts young adulthood smoking.

Personality dimensions explained $30 \%$ of total variance in smoking status. The percentage of prediction for nonsmoker's status was $68 \%$. However, the model successfully predicted and of smokers status in $57 \%$ of cases. On the whole, the percentage of total correct prediction was $63 \%$ (Table 6). Regression coefficients (B) with statistical significance (Wald) are shown in Table 6. The Wald criterion showed that only neuroticism in first step was significant predictor of smoking. The sign of the regression coefficients (B) and Odds Ratio (OR) indicated that smokers group were statistically higher on dimension of neuroticism. A positive value of coefficient means that the smokers are more emotional unstable and vice versa (Table 6).

Table 1. Correlation coefficients between subscales of the Inventory of college students' recent life experience

\begin{tabular}{llllll}
\hline & $\begin{array}{l}\text { Social } \\
\text { alienation }\end{array}$ & $\begin{array}{l}\text { Time } \\
\text { pressure }\end{array}$ & $\begin{array}{l}\text { Academic } \\
\text { failure }\end{array}$ & $\begin{array}{l}\text { Everyday } \\
\text { social conflict }\end{array}$ & $\begin{array}{l}\text { Academic } \\
\text { maladjustment }\end{array}$ \\
\hline $\begin{array}{l}\text { Social alienation } \\
\text { Time pressure }\end{array}$ & 1.00 & & & & \\
Academic failure & $0.23^{*}$ & 1.00 & & & \\
Everyday social conflict & $0.47^{*}$ & $0.28^{*}$ & 1.00 & 1.00 & 1.00 \\
Academic maladjustment & $0.42^{*}$ & $0.16^{*}$ & $0.41^{*}$ & $0.35^{*}$ & \\
\hline
\end{tabular}

$* \mathrm{p}<0.05$

Table 2. Descriptive parameters of the Inventory of college students' recent life experience

\begin{tabular}{lclll}
\hline Subscales & $\begin{array}{l}\text { Number } \\
\text { of items }\end{array}$ & $\begin{array}{l}\text { Range } \\
\text { of results }\end{array}$ & $\begin{array}{l}\text { Mean } \\
\text { (standard deviation) }\end{array}$ & $\begin{array}{l}\text { Reliability } \\
\text { (Cronbach alpha) }\end{array}$ \\
\hline Social alienation & 6 & $7-21$ & $10.61(\mathrm{sd}=2.99)$ & 0.77 \\
Time pressure & 13 & $14-48$ & $31.27(\mathrm{sd}=6.68)$ & 0.78 \\
Academic failure & 6 & $6-24$ & $11.70(\mathrm{sd}=3.28)$ & 0.75 \\
Everyday social conflict & 18 & $18-61$ & $30.50(\mathrm{sd}=6.99)$ & 0.80 \\
Academic maladjustment & 6 & $6-24$ & $12.70(\mathrm{sd}=3.48)$ & 0.70 \\
General experience of stress & 49 & $56-170$ & $96.78(\mathrm{sd}=18.45)$ & 0.89 \\
\hline
\end{tabular}


Nataša Šimić et al. / Journal of Social Sciences 2014, 10 (4): 162.171 DOI: $10.3844 /$ jssp.2014.162.171

Table 3. Descriptive parameters of personality trait for non-smokers and smokers

\begin{tabular}{|c|c|c|c|c|c|c|}
\hline \multirow[b]{2}{*}{ Personality traits } & \multicolumn{2}{|c|}{ Nonsmokers } & \multicolumn{2}{|c|}{ Smokers } & \multirow[b]{2}{*}{$\mathrm{F}(\mathrm{df})$} & \multirow[b]{2}{*}{$\mathrm{p}$} \\
\hline & M & SD & M & SD & & \\
\hline Extraversion & 32.44 & 6.51 & 33.15 & 6.38 & $F(1,198)=0.61$ & $p=0.43$ \\
\hline Agreeableness & 38.45 & 6.31 & 39.14 & 6.08 & $F(1,198)=0.63$ & $\mathrm{p}=0.42$ \\
\hline Conscientiousness & 35.54 & 5.90 & 34.09 & 6.08 & $F(1,198)=2.94$ & $\mathrm{p}=0.08$ \\
\hline Neuroticism & 19.00 & 5.77 & 21.43 & 7.21 & $F(1,198)=6.91$ & $\mathrm{p}<0.001$ \\
\hline Opennesses to experience & 35.15 & 5.21 & 35.19 & 5.45 & $F(1,198)=0.03$ & $p=0.95$ \\
\hline
\end{tabular}

Table 4. Descriptive parameters of stressful live events for non-smokers and smokers

\begin{tabular}{|c|c|c|c|c|c|c|}
\hline \multirow[b]{2}{*}{ Stressful live events } & \multicolumn{2}{|c|}{ Non-smokers } & \multicolumn{2}{|c|}{ Smokers } & \multirow[b]{2}{*}{$F(d f)$} & \multirow[b]{2}{*}{$\mathrm{p}$} \\
\hline & M & SD & M & SD & & \\
\hline Social alienation & 12.93 & 3.38 & 14.42 & 3.44 & $\mathrm{~F}(1,198)=9.58$ & $\mathrm{p}<0.001$ \\
\hline Time pressure & 18.35 & 4.72 & 18.93 & 4.83 & $F(1,198)=0.74$ & $\mathrm{p}=0.38$ \\
\hline Academic failure & 16.27 & 4.35 & 18.20 & 4.75 & $F(1,198)=9.01$ & $\mathrm{p}<0.001$ \\
\hline Everyday social conflict & 21.13 & 5.25 & 23.14 & 5.84 & $F(1,198)=6.58$ & $\mathrm{p}<0.001$ \\
\hline Academic maladjustment & 8.92 & 2.90 & 8.85 & 2.67 & $F(1,198)=0.03$ & $\mathrm{p}=0.85$ \\
\hline Overall score & 93.37 & 17.41 & 100.26 & 18.92 & $F(1,198)=7.17$ & $\mathrm{p}<0.001$ \\
\hline
\end{tabular}

Table 5. Correlation coefficients between personality traits and stressful life events

\begin{tabular}{lllllc}
\hline & Extraversion & Agreeableness & Conscientiousness & Neuroticism & Opennesses to experience \\
\hline Social alienation & $-0.22^{*}$ & -0.03 & -0.14 & $0.42^{*}$ & 0.01 \\
Time pressure & 0.08 & 0.09 & 0.10 & $0.22^{*}$ & 0.02 \\
Academic failure & $-0.24^{*}$ & 0,03 & $-0.28^{*}$ & $0.50^{*}$ & -0.00 \\
Everyday social conflict & -0.03 & -0.11 & $-0.19^{*}$ & $0.38^{*}$ & -0.08 \\
Academic maladjustment & -0.07 & -0.00 & $-0.17^{*}$ & $0.27^{*}$ & -0.02 \\
\hline
\end{tabular}

$* \mathrm{p}<0.05$

Table 6. Results of hierarchic logistic regression analysis of predicting smoking status

\begin{tabular}{|c|c|c|c|c|c|c|}
\hline & $\mathrm{B}$ & St. Error & Wald & df & $\mathrm{p}$ & OR \\
\hline \multicolumn{7}{|l|}{ Predictors } \\
\hline \multicolumn{7}{|l|}{ First step } \\
\hline Extraversion & -0.25 & 0.50 & 0.24 & 1 & 0.62 & 0.77 \\
\hline Agreeableness & -0.01 & 0.47 & 0.00 & 1 & 0.97 & 0.98 \\
\hline Conscientiousness & 0.45 & 0.40 & 1.27 & 1 & 0.25 & 1.57 \\
\hline Neuroticism & 0.59 & 0.29 & 4.07 & 1 & $0.04 *$ & 1.81 \\
\hline \multirow[t]{4}{*}{ Opennesses to experience } & 0.14 & 0.42 & 0.11 & 1 & 0.73 & 1.15 \\
\hline & \multicolumn{4}{|c|}{$\chi^{2}(\mathrm{df})$} & \multicolumn{2}{|c|}{$7.68(\mathrm{df}=5)^{*}$} \\
\hline & \multicolumn{3}{|c|}{$\%$ of correct prediction } & & \multicolumn{2}{|c|}{$63 \%$} \\
\hline & Cox an & & & 0.30 & & \\
\hline \multicolumn{7}{|l|}{ Predictors } \\
\hline \multicolumn{7}{|l|}{ Second step } \\
\hline Extraversion & -0.32 & 0.52 & 0.37 & 1 & 0.53 & 0.72 \\
\hline Agreeableness & -0.34 & 0.50 & 0.46 & 1 & 0.49 & 0.71 \\
\hline Conscientiousness & 0.41 & 0.44 & 0.87 & 1 & 0.35 & 1.50 \\
\hline Neuroticism & 0.21 & 0.33 & 0.43 & 1 & 0.51 & 1.24 \\
\hline Opennesses to experience & 0.22 & 0.44 & 0.25 & 1 & 0.61 & 1.25 \\
\hline Social alienation & 0.67 & 0.39 & 2.94 & 1 & 0.08 & 1.97 \\
\hline Time pressure & -0.19 & 0.30 & 0.42 & 1 & 0.51 & 0.81 \\
\hline Academic failure & 0.84 & 0.42 & 4.00 & 1 & $0.04 *$ & 2.32 \\
\hline Everyday social conflict & 0.35 & 0.46 & 0.58 & 1 & 0.44 & 1.42 \\
\hline \multirow[t]{4}{*}{ Academic maladjustment } & -0.60 & 0.27 & 4.79 & 1 & $0.02 *$ & 0.54 \\
\hline & \multicolumn{4}{|c|}{$\chi^{2}(\mathrm{df})$} & \multicolumn{2}{|c|}{$21,75(\mathrm{df}=10)^{* *}$} \\
\hline & \multicolumn{4}{|c|}{$\%$ of correct prediction } & \multicolumn{2}{|c|}{$65 \%$} \\
\hline & \multicolumn{4}{|c|}{ Cox and Snell $\mathrm{R}^{2}$} & \multicolumn{2}{|l|}{0,35} \\
\hline
\end{tabular}

$* \mathrm{p}<0.05 ; * \mathrm{*}<0.01$ 
Furthermore, after everyday stressful life events were entered in the second step, there was statistically significant improvement in prediction $\left(\chi^{2}=21.75\right.$; df $=$ $10 ; \mathrm{p}<0.01 ; \mathrm{R} 2=0.35)$. Total number of correct estimation in category of non-smokers and group of smokers increased for $2 \%$ and was $65 \%$. Based on these predictors, percentage of correct prediction for nonsmokers is now $65 \%$, while for smokers $64 \%$. In the full model, the only significant individual predictors were academic failure and maladjustment. This means that smokers who experience more academic failure will more smoke. Negative value of B coefficient for predictor of academic maladjustment also indicate that smokers will experience more academic maladjustment if they smoke more and vice versa. However, academic maladjustment was not associated with the number of smoked cigarettes, which is a suppressor of predictor variables in correlations with: Neuroticism $(r=0.20$, $\mathrm{p}<0.05)$, social alienation $(\mathrm{r}=0.37, \mathrm{p}<0.05)$, time pressure $(\mathrm{r}=0.38, \mathrm{p}<0.05)$, academic failure $(\mathrm{r}=0.50$, $\mathrm{p}<0.05)$ and everyday social conflicts $(\mathrm{r}=0.41, \mathrm{p}<0.05)$.

\section{Discussion}

College students can experience many social and academic challenges, as well as numerous psychosocial stressors which involve interpersonal problems, such as conflict with peers and professor, weaker success than expected, excessive demands of different courses. The aforementioned stressors can have a negative impact on the number of students' behaviors. Most previous studies have tested specific stressors related to education of adolescents (Compas et al., 2001; De Anda et al., 2000; Elias, 1989; Hess and Copeland, 2009). However, the lack of these studies was that they did not take into account some short-term stressors that persist for some time. Prediction of a number of negative effects of everyday stress situations could be superior to major stressful life events.

One of the aims of this study was to examine the factor structure of the scale, which includes an assessment of the specific stressors that students experience every day. The main reason for using this scale in was its suitability among students' population, as well as using in numerous studies on students of different country, student of Switzerland (Vollrath, 2000), England (Lay and Safdar, 2003), U.S. (Bodenhorn et al., 2007) and China (Cheng, 2003). Factor analysis in this study yielded five factors interpreted as social alienation, time pressure, academic failure, everyday social conflicts and academic maladjustment. Obtained factorial structure was partially in accordance with the original structure revealed by (Kohn et al., 1990). Previous studies did not also confirm the original factor structure. For example, Bodenhorn et al. (2007) obtained six factors:
Relationship problems, social alienation, negotiation, time pressure, academic failures and disappointments. Possible reason for different factor structure obtained in this and other studies (Bodenhorn et al., 2007; Cheng, 2003; Lay and Safdar, 2003; Vollrath, 2000) may be culturally conditioned, as well as explained by differences of stressor tested on different student's sample. In future studies it is certainly necessary to test the factor structure of the scale. Reliability of the scale was also satisfactory and similar to those revealed in previous studies (Bodenhorn et al., 2007; Kohn et al., 1990; Osman et al., 1994).

Correlation analysis showed that the extracted factors correlated significantly with each other which mean that there is one general stress factor in students. The results of factor analysis with a fixed number of common factors in this study also showed and one-factor solution. Among the highest correlations in the study were those between factors of social alienation, everyday social conflicts, academic disappointments and failures, as well as those between academic failure and everyday social conflicts, academic disappointments and maladjustment. These results indicate that the imperative to success in education should regulation social relations and academic failure can lead to worse social relations. Poor social relations can also have significantly negative effect on academic performance. Experiences of failure and adverse social relationships represent sources of stress, which are, as the results of this study shows, significantly correlated with the smoking. As for the factor of time pressure, there were obtained significant, but lower correlation with the other factor of stress scale. This could mean that sense of time pressure exists and varies according to other aspects of the stress, but to a lesser extent as compared to other stress factors. Earlier studies also indicate that stressors related to achieving success in education are the greatest stressors among adolescents (Conner et al., 2009; De Anda et al., 2000).

Furthermore, the only significant difference in personality traits between smokers and non-smokers was obtained for the dimension of neuroticism. Smokers achieved higher scores on the neuroticism scale compared to non-smokers. Correlation analysis also showed low, but only significant correlation between neuroticism and the number of smoked cigarettes. In accordance with this are and the results of logistic analysis, which showed that neuroticism was only individual significant predictor of smoking status. If students are more neurotic they will smoke more. Neurotic individuals may have a high intensity of negative emotions, as well as unsuccessful mechanisms of self-regulation so it could be possible that they use cigarettes for reduce the level of negative affectivity (Rondina et al., 2007). Furthermore, neurotic people may be afflicted by negative feelings of their ability and 
situation which may further increase the level of stress and dissatisfaction with themselves, as well as cause difficulty in achieving academics goals and raise the consummation of tobacco products. In support of the above are the results of correlation analysis that showed statistically significant correlation between neuroticism and experience of everyday stressors in students. McCrae (1990; Hudek-Knežević and Kardum, 2006) acknowledged that neuroticism, as one of the basic personality traits, largely affects on the behavior of individuals. Therefore, this dimension should be included in studies of stress and coping, since it could largely explain the effects of coping on adaptation outcomes. Neuroticism in interaction with everyday stressful events could be one of the main determinants of smoking status.

Regarding the differences between non-smokers and smokers in other dimensions of personality, the most consistent difference was obtained for extraversion, whereby, smokers archived higher scores (Van Loon et al., 2001; Vink et al., 2003). Eysenck (1981) argued that individuals high in extraversion would smoke in search for stimulation. However, the results of this study are not in accordance with the above. Obtained results are in line with studies that indicate a decrease in the relationship between extraversion and smoking. Because smoking is considered as socially undesirable habit, it is possible that extravert reduce the craving for smoking as the results to increase the number of social interactions (Gilbert and Gilbert, 1995; Terracciano and Costa, 2004). Results of this study also showed no differences between smokers and non-smokers on the dimensions of conscientiousness, openness to experience and agreeableness. Results across studies are mixed (Stewart and Livson, 1996; Vollrath and Torgersen; Vollrath et al., 1999), but when differences were found, smokers had to lower scores on above mention dimensions compared to those who never smoked.

When it comes to the experience of stressful life events, difference between smokers and non-smokers were revealed in frequency of experiencing social alienation, social conflicts and academic failure. Smokers had higher scores results in comparison to nonsmokers. This leads to the conclusion that smokers are more socially alienated and have a poorer quality of social relationships and probably lower social support in relation to non-smokers. It is well known that many students with low level of social support are exposed to many risky health behavior, such as cigarette smoking, alcohol, drugs and so on (Wills, 1990). Lack of social support, support of friends and parents, could play important role in initiation and maintenance of smoking (Kobus, 2003; Simons-Morton, 2002). Also, negative affectivity characterized in persons higher on neuroticism may also lead them to less social support and experience of more conflicts. Therefore, future research should examine the impact of social support on the experience of stress and smoking.

Smoking could represent a way of coping with academic problems. In this sense, smoking would be a direct response to social problems and difficulties in achieving academic goals. According to this it is possible that students start smoking as an effort to cope with these difficulties. An important feature of this research is that we examined, for the first time, experience of academic failure and maladjustment in students smokers and non-smokers. Academic maladjustment and failure were found as significant predictor of smoking. Academic maladjustment acted as suppressor variable since it was in zero correlation with smoking status. However, this variable was a significant predictor in explaining the variance of criteria because it removes the invalid part of the variance regarding the variables with which correlate, which is associated with the criterion. This is variable neuroticism, which is in a significant correlation with smoking status, as well as academic maladjustment.

Previous studies (Chapman et al., 2009; Cox et al., 2007; Houri and Hammoud, 2005) have also shown that smoking is associated with lower academic achievement, however, other factors during the study, such as the adjustment to college, relationships with colleagues are not take into account. Future longitudinal studies should examine contribution of study difficulties to a variety of risky behaviors that have negative effects on the students' health.

Studying is perceived as stressful event since students may cope with various changes in the academic and social environment. Due to the different difficulties of psychosocial nature, abuse of various drugs may represent one way of coping. In fact, higher proportion of young people start earlier with consummation of an addictive substances. Also, there is an increasing number of youth that are trying to relieve numerous extensive everyday tasks by smoking due to the positive effect of nicotine on the reduction of stress and tension. Therefore, further research need to get insight into a variety of individual and environmental risk, as well as protective factors of nicotine addiction and enable the development of more effective prevention programs.

In the end, it is necessary to point out some methodological limitations of the study. Specifically the sample is relatively homogenous considering the age of population. One of the limitations is also the measure of smoking status. Although this measure is used in previous studies, it does not cover some other aspects of smoking, which should future studies take into account. Finally, it can be said that interactions, but not independently, influence of different psychosocial factors have a significant impact on smoking. By examining their interaction effects, future longitudinal studies could 
contribute to improvement of the development successful prevention programs of smoking, as well as improve academic achievement and reduce stress during study.

\section{Conslusion}

The results of the study show that neuroticism could be an important variable in initiation and maintenance of smoking. Regarding the daily stressful life events, the results showed significant differences in their perception between smokers and nonsmokers. Smokers obtained higher scores on a scale of social alienation, academic failure and everyday social conflicts. Academic failure and academic maladjustment also proved to be significant predictors of smoking.

\section{Acknowledgement}

The researchers are thankful to the university and to students who participated in the investigation.

\section{Author's Contributions}

All authors equally contributed in this work.

\section{Ethics}

This article is original and contains unpublished material. The corresponding author confirms that all of the other authors have read and approved the manuscript and no ethical issues involved.

\section{References}

Akram, W., S.E. Yacoub, A.A.A. Al Saedi and Y.A. Raheem, 2011. The trend of smoking behavior and its relation to health knowledge among medical and literature colleges. Am. J. Infect. Dis., 7: 45-50. DOI: 10.3844 /ajidsp.2011.45.50

Allen, S. and B. Heibert, 1991. Stress and coping in adolescents. Canad. J. Counsel., 25: 19-32.

ALA, 2002. Adolescent smoking statistics. American Lung Association

Arai, Y., T. Hosokawa, A. Fukao, Y. Izumi and S. Hisamichi, 1997. Smoking behaviour and personality: A population-based study in Japan. Addiction, 92: 1023-1033. DOI: 10.1111/j.1360-0443.1997.tb02982.x

Baron-Epel, O. and A. Haviv-Messika, 2004. Factors associated with age of smoking initiation in adult populations from different ethnic backgrounds. Eur. J. Public Health, 14: 301-305.

DOI: 10.1093 /eurpub/14.3.301

Bodenhorn, N., Y. Miyazaki, K. Ng and C. Zalaquett, 2007. Analysis of the inventory of college students' recent life experiences. Multicultural Learn. Teach., 2: 65-77. DOI: 10.2202/2161-2412.1022
Booth-Kewley, S. and R.R. Vickers, 1994. Associations between major domains of personality and health behavior. J. Personality, 62: 282-298. DOI: $10.1111 / \mathrm{j} .1467-6494.1994 . t b 00298 . x$

Botvin, G., J.A. Epstein, S.P. Schinke and T. Díaz, 1994. Predictors of cigarette smoking among inner-city minority youth. J. Dev. Behav. Pediatr., 15: 67-73. PMID: 8034769

Burch, G., D.R. Hemsley and P.J. Corr, 2008. An antisocial personality for an anti-social habit? The relationship between multi-dimensional schizotypy, "normal" personality, ad cigarette smoking. Int. J. Clin. Health Psychol., 8: 23-35.

Chapman, B., K. Fiscella, P. Duberstein and I. Kawachi, 2009. Education and smoking: Confounding or effect modification by phenotypic personality traits? Ann. Behav. Med., 38: 237-248. DOI: $10.1007 / \mathrm{s} 12160-009-9142-3$

Cheng, C., 2003. Cognitive and motivational processes underlying coping flexibility: A dual-process model. J. Personality Soc. Psychol., 84: 425-438. DOI: $10.1037 / 0022-3514.84 .2 .425$

Compas, B.E., J.K. Connor-Smith, H. Saltzman, A.H. Thomsen and M.E. Wadsworth, 2001. Coping with stress during childhood and adolescence: Problems, progress and potential in theory and research. Psychol. Bull., 127: 87-127. DOI: $10.1037 / 0033-2909.127 .1 .87$

Conner, J., D. Pope and M. Galloway, 2009. Success with less stress. Educ. Leadership, 67: 54-57.

Costa, P.T. and R.R. McCrae, 1992. Revised NEO Personality Inventory (NEO PI-R) and NEO FiveFactor Inventory (NEO-FFI). 1st Edn., Psychological Assessment Resources, Odessa, Fla., pp: 101.

Costa, P.T., R.R. McCrae and P.A.R. Staff, 2000. NEO PI-R Interpretive Report. NEO Software System. 1st Edn., Psychological Assessment Resources, Odessa, FL.

Cosci, F., A. Corlando, E. Fornai, F. Pistelli and P. Paoletti et al., 2009. Nicotine dependence, psychological distress and personality traits as possible predictors of smoking cessation. Results of a double-blind study with nicotine patch. Addict Behav., 13:28-35. DOI: 10.1016/j.addbeh.2008. 08.003

Cox, R.G., L. Zhang, W.D. Johnson and D.R. Bender, 2007. Academic performance and substance use: Findings from a state survey of public high school students. J. School Health, 3: 109-115. DOI: $10.1111 / \mathrm{j} .1746-1561.2007 .00179 . \mathrm{x}$

De Anda, D., S. Baroni, L. Boskin, L. Buchwald and J. Morgan et al., 2000. Stress, stressors and coping among high school students. Children Youtgh Services Rev., 22: 441-463. DOI: $10.1016 / \mathrm{S} 0190-7409(00) 00096-7$ 
Elias, M., 1989. Schools as a source of stress to children: An analysis of causal and ameliorative influences. J. School Psychol., 27: 393-407.

DOI: $10.1016 / 0022-4405(89) 90016-2$

Eysenck, 1981. The Causes and Effects of Smoking. 1st Edn., Sage Publications, MT Smith, ISBN-10: 0803914547, pp: 397.

Gilbert, D.G. and B.O. Gilbert, 1995. Personality, psychopathology and nicotine response as mediators of the genetics of smoking. Behav. Genet., 25: 13347. DOI: $10.1007 / \mathrm{BF} 02196923$

Hagger-Johnson, G., B.M. Bewick, M. Conner, D. O'Connor and D. Shickle, 2012. School-related conscientiousness, alcohol drinking and cigarette smoking in a representative sample of English school pupils. Br. J. Health Psychol., 17: 644-665. DOI: $10.1111 / \mathrm{j} .2044-8287.2011 .02061 . x$

Hess, R.S. and E.P. Copeland, 2009. Students' stress, coping strategies and school completion: A longitudinal perspective. School Psychol. Q., 16: 389-405. DOI: $10.1521 /$ scpq.16.4.389.19899

Hudek-Knežević, J. and I. Kardum, 2006. Psihosocijalne odrednice tjelesnog zdravlja-Stres i tjelesno zdravlje. Slap, Jastrebarsko.

Houri, A. and M. Hammoud, 2005. Addictive behaviors amongst university students: Contributing factors, student's perception and addiction rates. J. Soc. Sci., 1: 105-113. DOI: $10.3844 /$ jssp.2005.105

Kawakami, N., A. Takai, N. Takatsuka and H. Shimizu, 2000. Eysenck's personality and tobacco/nicotine dependence in male eversmokers in Japan. Addictive Behav., 25: 585-591. DOI: $10.1016 / \mathrm{S} 0306-4603(99) 00019-2$

Kobus, K., 2003. Peers and adolescent smoking. Addiction, 98: 37-55. DOI: 10.1046/j.1360-0443.98.s1.4.X

Kohn, P.M., K. Lafreniere and M. Gurevich, 1990. The inventory of college students' recent life experiences: A decontaminated hassles scale for a special population. J. Behav. Med., 16: 619-630. DOI: $10.1007 /$ BF00844738

Kubicka, L., Z. Matejcek, Z. Dytrych and Z. Roth, 2001. IQ and personality traits assessed in childhood as predictors of drinking and smoking behaviour in middle-aged adults: A 24-year follow-up study. Addiction, 96: 1615-1628. DOI: $10.1046 /$ j. 1360-0443.2001.961116158.x

Lay, C.H. and S.F. Safdar, 2003. Daily hassles and distress among college students in relation to immigrant and minority status. Current Psychol. Res. Rev., 22: 3-22. DOI: $10.1007 / \mathrm{s} 12144-003-1009-3$

Malouff, J.M., E.B. Thorsteinsson and N.S. Schutte, 2006. The five-factor model of personality and smoking: A meta-analysis. J. Drug Educ., 36: 4758. DOI: 10.2190/9EP8-17P8-EKG7-66AD
McCrae, R., 1990. Controlling neuroticism in the measurement of stress. Stress Med., 6: 237-241. DOI:10.1002/smi.2460060309

Mejovšek, M., 2003. Uvod U Metode Znanstvenog Istraživanja U Društvenim I Humanističkim Znanostima. 1st Edn., Naklada Slap, Jastrebarsko, ISBN-10: 9531912238, pp: 272.

Misra, R., 2000. Academic stress of college students: Comparison of student and faculty perceptions. College Student J., 21: 1-10.

Naing, N.N., Z. Ahmad, R. Musa, F.R. Abdul Hamid, and H. Ghazali et al., 2004. Factors related to smoking habits of male adolescents. Tob Induc Dis., 2: 133-140. DOI: 10.1186/1617-9625-2-3-133

Osman, A., F.X. Barrios, J. Longnecker and J.R. Osman, 1994. Validation of the inventory of college students' recent life experiences in an American college sample. J. Clin. Psychol., 50: 856-863. DOI: $10.1002 / 1097-4679(199411) 50: 6<856:: A I D-$ JCLP2270500607>3.0.CO;2-C

Paavola, M., P. Vartiainen and P. Puska, 1996. Predicting adult smoking: The influence of smoking during adolescent and smoking among friends and family. Health Educ. Res., 11: 309315. DOI: $10.1093 /$ her/11.3.309

Papakyriazi, E. and S. Joseph, 1998. Individual differences in personality among smokers and their personality among smokers and their association with smoking motivation, social skills deficit and self-efficacy to quit. Personality Individual Differences, 25: 621-626. DOI: $10.1016 / \mathrm{S} 0191-8869(98) 00046-4$

Patton, D., G.E. Barnes and R.P. Murray, 1997. A personality typology of smokers. Addictive Behav., 2: 269-273. DOI: 10.1016/S0306-4603(96)00004-4

Pierce, J.P., W.S. Choi, E.A. Gilpin, A.J. Farkas and R.K. Merritt, 1996. Validation of susceptibility as a predictor of which adolescents take up smoking in the United States. Health Psychol., 15: 355-361. DOI: $10.1037 / 0278-6133.15 .5 .355$

Rondina, R.C., R. Gorayeb and C. Bothelo, 2007. Psychological characteristics associated with tobacco smoking behavior. Braz. J. Pulmonol., 33: 592-601. DOI: 10.1590/S1806-37132007000500016

Simons-Morton, B.G., 2002. Prospective analysis of peer and parent influences on smoking initiation among early adolescents. Prevention Sci., 3: 275283. DOI: $10.1023 / \mathrm{A}: 1020876625045$

Spielberger, C.D. and G.A. Jacobs, 1982. Personality and smoking-behavior. J. Personality Assess., 46: 396-403. DOI: 10.1207/s15327752jpa4604_11

Steptoe, A. and J. Wardle, 2001. Health behaviour, risk awareness and emotional well-being in students from Eastern Europe and Western Europe. Soc. Sci. Med., 53: 1621-1630. DOI: 10.1016/S0277-9536(00)00446-9 
Stewart, L. and N. Livson, 1996. Smoking and rebelliousness: A longitudinal study from childhood to maturity. J. Consult. Psychol., 30: 225-229. DOI: $10.1037 / \mathrm{h} 0023371$

Terracciano, A. and P.T. Costa, 2004. Smoking and the five-factor model of personality. Addiction, 99: 472-481. DOI: 10.1111/j.1360-0443.2004.00687.x

Van Loon, A.J., M. Tijhuis, P.G. Surtees and J. Ormel, 2001. Personality and coping: Their relationship with lifestyle risk factors for cancer. Personality Individual Differences, 31: 541-553. DOI: 10.1016/S0191-8869(00)00158-6

Vink, J.M., G. Willemsen, R.C. Engels and D.I. Boomsma, 2003. Smoking status of parents, siblings and friends: Predictors of regular smoking? Findings from a longitudinal twin-family study. Twin Res., 6: 209-217. PMID: 12855070

Vollrath, M., 2000. Personality and hassles among university students: A three-year longitudinal study. Eur. J. Personality, 14: 199-215. DOI: 10.1002/1099-0984(200005/06)14:3<199::AIDPER372>3.0.CO;2-B
Vollrath, M., D. Knoch and L. Cassano, 1999. Personality, risky health behaviour and perceived susceptibility to health risks. Eur. J. Personality, 13: 39-50. DOI: 10.1002/(SICI)10990984(199901/02)13:1<39::AID-PER328>3.0.CO;2-J

Vollrath, M. and S. Torgersen, 2002. Who takes health risks? A probe into eight personality types. Personality Individual Differences, 32: 1185-1197. DOI: $10.1016 / \mathrm{S} 0191-8869(01) 00080-0$

Wills, T.A., 1990. Multiple networks and substance use. J. Soc. Clin. Psychol., 9: 78-90. DOI: $10.1521 /$ jscp.1990.9.1.78

Wang, C.D. and C. Castaneda-Sound, 2008. The role of generational status, self-esteem, self-efficacy and perceived social support in college students' psychological well-being. J. Coll. Couns, 11: 101118. DOI: $10.1002 / \mathrm{j} .2161-1882.2008 . t b 00028 . x$

WHO, 2002. The World Health Report 2002-Reducing Risks, Promoting Healthy Life. 1st Edn., World Health Organization, Geneva. 